\title{
Explaining political attention allocation with the help of issue character: evidence from the European Council
}

\author{
PETYA ALEXANDROVA* \\ Postdoctoral Researcher, Institute of Political Science, Leibniz University of Hannover, Chair for Comparative and \\ German Politics, Hannover, Germany
}

\begin{abstract}
Policy issues compete for the attention of political actors, and the size of the agenda an issue can occupy is largely determined by the way in which it is defined. This logic constitutes a simple agenda-setting model in which factors related to the participants in the policy process and their context influence the attention a single issue receives after being problematised. In order to be able to apply this model to the construction of a whole agenda, we need to add an intermediate step. This study proposes to do so by incorporating the notion of issue character and offers an empirical application of the adapted model to the European Council, a crucial informal player in European Union (EU) agenda setting. Using a dimensionality reduction technique, the composition of the agenda is broken down to two constitutive dimensions - core vs. non-core themes of government and economic vs. noneconomic character. Since the first structuring element is in line with existing knowledge and the role expectations for the European Council, the analysis concentrates on the second type. Changing saliency levels of the economic issue character of the agenda are used as a dependent variable in a model, including predictors related to the nature of the institution and contextual factors. The results show that leftist European Council party ideology and growing government deficit in the EU contribute to the increasing prominence of the economic dimension, which in turn explains rising levels in attention to various issues, especially of the non-core themes type.
\end{abstract}

Keywords: agenda setting; policy agenda; issue character; European Council

\section{Introduction}

A key notion of agenda-setting theory holds that attention of political actors is scarce and issues compete for access to the agenda (Cobb and Elder, 1971; Kingdon, 1995; Jones, 2001). This results in an erratic pattern of attention shifts across topics, over long time periods, and a disproportionate representation of various matters on the agenda. The chance of success of a single issue is seen as conditional upon various factors, ranging from preferences of political actors, through institutional architectures, to external events (see e.g. Birkland, 1997; Talbert and Potoski, 2002; Green-Pedersen and Mortensen, 2010). The mechanism, via which changes on the agenda occur, is rooted in recognition and interpretation of new information, or in

* E-mail: p.alexandrova@ipw.uni-hannover.de 
other words the intrusion of new issues or new attributes of existing issues (Jones and Baumgartner, 2005). Attribute intrusion, in practice, means redefining an issue in light of the emergence of a dimension of policy making, which has previously not been considered relevant (Rochefort and Cobb, 1994). This can be seen as a synonym of framing - the primary framework through which an issue is perceived is used to describe this issue (Goffman, 1974).

The idea that every matter placed on the political agenda is wrapped in attributed meanings, ascribed by the actors involved in the agenda-setting battle, has been intensively analysed across various domains (e.g. Plein, 1991; Jeon and HaiderMarkel, 2001; Strom and Cook, 2004; Scholten and Timmermans, 2010). Within the European Union (EU) context, a number of case studies have explored the linking of different types of frames to issues, the struggles for imposing particular frames, and the effects thereof on policy choices (e.g. Black, 2009; Princen, 2010; Rhinard, 2010; Daviter, 2011; Moschella, 2011; Littoz-Monnet, 2012; Candel et al., 2014; Cerna and Chou, 2014). But all of these studies focus on particular issues and their journeys throughout the agenda-setting stage of the policy process. While the issue definition literature is reconciled with the idea of issue competition, it has failed to theorise on a macro perspective to framing, in terms of an overall agenda.

On the other hand, the policy typology literature has proposed the concept of issue character, developed on the basis of cross-sectional issue comparisons, to explain different modes of policy making via inherent structural differences between policies. This strain of thought is not directly associated with the concepts of agenda setting and framing. But as Jones and Baumgartner (2005) note, with their focus on the logic behind topics appearing in public debates, scholars in this field, in fact, study agenda success. Policy typologies have so far been applied to the public, the media, or interest groups' agendas (see e.g. Carmines and Stimson, 1980; Sigelman et al., 1992; Baum, 2002), while the agendas of political institutions, which are subject to the same behavioural patterns (Jones and Baumgartner, 2005), have generally stayed beyond the focus. This is also true for the EU, where research on organised interests is most advanced in this respect and features of policy issue context are seen to have an effect on lobbying achievements (Mahoney, 2007; Klüver, 2011).

This study presents an attempt to bridge these two strains of literature by proposing to use the notion of issue character as an intervening element between the factors, which potentially affect agenda setting and the structure of the overall agenda of political institutions. The focus of the paper is on a single EU institution the European Council. With its crucial role in determining the overall agenda of the EU (Werts, 2008; Nugent, 2010; Eggermont, 2012), understanding how the European Council distributes its attention and why it follows particular lines has implications for the broader EU agenda-setting processes. Recent research has demonstrated that core themes of government seem to gain more attention than all other topics (Alexandrova et al., 2012). But we need additional research before we 
can assume that this is the only issue character typology that explains the allocation of attention.

The paper proceeds as follows: after elaborating on the role of issue character as the missing component in the theory of political attention allocation, and discussing the existing knowledge of agenda dynamics in the European Council, the structure of the analysis is spelled out. The study assumes a two-step backward-moving approach. First, it uses longitudinal data on the allocation of attention in the European Council to disentangle the dimensions of issue character, which determine the levels of attention. Two dimensions are discovered, one of which corresponds well with findings from existing research. The second issue character type is less important overall but shows a fluctuating pattern of saliency over the years. After interpreting its meaning, the second step of the analysis evaluates the extent to which various factors predict the rises and falls in its prominence. The study concludes with a discussion of the implications of the empirical findings and the use of the new theoretical model.

\section{From attribute intrusion to issue character}

The definition of an issue is one of the crucial determinants of the level of attention allocated to it (Rochefort and Cobb, 1994). Peters $(1994,2001)$ argues that the EU is a political system different from those of nation states in many respects as far as agenda setting is concerned. Notably, issue definition is even more important in the EU because it determines the way and level on which the issue will be tackled. In particular, '[t]he internal fragmentation, overlapping competencies and multiple logics of political representation of supranational actors regularly ensure that alternative issue definitions remain in play simultaneously' (Daviter, 2011: 169). These peculiarities have made the EU's political system an attractive arena for scholars, who focus on the effects of unclear or changing jurisdictional boundaries and venue interactions on issue attention and problem formulation or framing (see e.g. Wendon, 1998; Sheingate, 2000; Princen, 2010; Rhinard, 2010).

The most common approach to the empirical study of framing consists of a focus on a single issue or a larger topic, which is subject to different frames over time, and exploration of how these frames have evolved and competed across venues. To take an EU example, Daviter's (2011) study of the European Commission's biotechnology policy discovers three dominant frames. A struggle between an environmental and an economic frame results in subsequent success intervals for each of them, and is finally overturned by a third frame of consumer choice. These findings, while incredibly insightful for scholars interested in biotechnology policy, bare the usual pitfalls of case-study research - they are not generalisable to all issues on the political agenda.

This shortcoming has long-ago been recognised by Theodore J. Lowi in his critical review of 'the problem of uniqueness' (1964: 311). Lowi (1964, 1972) argued that in order to understand political conflict fully, we need to consider characteristics related to the type of issue. And these characteristics should be formulated in such a way that they can apply to all points on the agenda. While his proposed solution, namely 
(a)

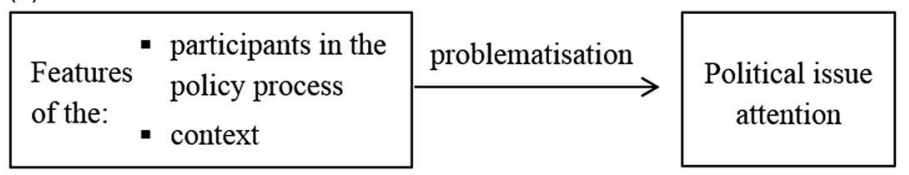

(b)

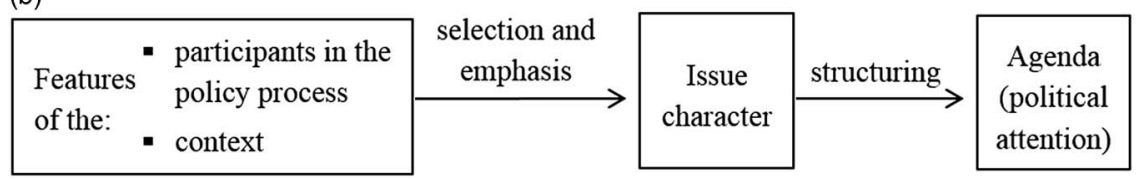

Figure 1 Agenda-setting models for a single issue (a) and a whole agenda (b).

the use of a distinction between distributive, (constituent, ${ }^{1}$ ) regulatory, and redistributive policies, has encountered critique and been subject to revisions (e.g. Wilson, 1973, 1980; Kjellberg, 1977), the notion that there are certain types of issue characteristics, which structure overall political debates and agendas, merits attention. Markedly, Lowi's approach does not advocate exclusive categories of policy types but rather hints at latent dimensions of policy (Lowi, 1972). The four groups are a matrix based on two dimensions: likelihood of coercion (immediate vs. remote) and its applicability to individual conduct vs. the environment of conduct.

The issue character concept can be a useful tool for expanding the framing literature towards studies of overall agenda dynamics rather than evolutionary monologues of single topics. In order to grasp its place in the agenda-setting process, we should start with examining the standard logic of explaining the level of political attention on a single issue within a single policy venue. Figure 1 (a) presents this in a simplified model. Political attention is determined by factors associated with the participants in the policy process (e.g. party ideology, individual preferences, etc.) and the context (e.g. issue development indicators, focusing events, legacy in terms of previous discussions of the same issue, decision-making rules, etc.). These two categories correspond to the two sources of bias in institutional agendas suggested by Cobb and Elder (1971). Some of the factors are activated by the agenda setter to produce problematisation of an issue, that is, to convert an issue into a policy problem. This process of issue (re)definition eventually determines which topics reach the agenda and are subject to decision and which topics are left out (Schattschneider, 1960; Bachrach and Baratz, 1962). It involves attribute intrusion as 'a consequence of the disproportionate updating of the incomplete "basket" of indicators that decision makers are monitoring' (Jones and Baumgartner, 2005: 56). ${ }^{2}$ A straightforward example of this agenda-setting model can be found in a study of

\footnotetext{
1 This category was added in Lowi's later work of 1972.

${ }^{2}$ Generally, this can be expected to go hand in hand with issue expansion, but such a prospect is rather uncommon to the EU system (Princen, 2007).
} 
the effect of economic conditions, public opinion (most important problem measure) with respect to the economy, and congressional ideology on attention to economic issues in US congressional hearings (Jones and Baumgartner, 2005).

However, when we move to the whole agenda, both conceptually and methodologically it is impossible to use the factors to directly predict agenda composition. One solution would be to analyse all topics on the agenda separately and then induce general findings. But such an approach is extremely labour-intensive and, more importantly, inherently flawed because it infringes on the core assumption in agenda-setting theory, that attention is scarce and allocating more of it to one issue means depriving another one. Therefore, we need an intermediary step in the model that represents a unifying (clustering) aspect for all policy areas. Such an option can be derived from the notion of issue character as a structuring inherent dimension of policies. Thus, in the agenda-setting model, which corresponds to the whole agenda, the distribution of attention will be explained by issue character, the prominence of which is a function of factors related to the participants in the policy process and the context.

Figure 1(b) displays this model. Its starting point is the same as in the single-issue model - different indicators, events, institutional rules, etc. and traits of the actors with agenda-setting power can act as drivers for attention dynamics. But their effect on attention is not direct; it is channelled through issue character. The key actors in the policy venue select certain contextual elements through the prism of their own biases and this process results in emphasising a particular issue character dimension. The extent to which this dimension is emphasised (to the expense of other possible dimensions) determines the rises and falls in attention to multiple issues, or in other words structures the overall agenda.

Issue character is a way of describing the underlying line of classification, which divides and brings together matters on the agenda. The concept does not assume a static phenomenon. The saliency of a particular issue character can be expected to vary over time. The prominence is determined by the desires of the participants in the agenda-setting process, features of their environment, and interactions between the two. The specific kinds of issue character, which are relevant for a particular venue need to be empirically verified. ${ }^{3}$ They are likely to be at least in part a function of the role or jurisdictional authority of the venue. But essentially, what issue character will be emphasised is also a political choice of the actors involved in the agenda-setting process. Just like the level of its prominence, the employment of one or another type of issue character is a decision in the hands of the actor(s) with agenda-setting power, influenced by features of this (these) actor(s) and the institutional context. Therefore, once in action, a particular dimension might be there to stay for the whole life-cycle of a policy venue or be present only during a limited period.

\footnotetext{
${ }^{3}$ It is not impossible for only a single dimension to be considered applicable.
} 
The literature has offered multiple examples of issue character typologies, which can be used to determine developments in public policy. Lowi's $(1964,1972)$ original conceptualisation identified two lines - proximity of coercion (more vs. less remote) and its applicability (whether coercion is exercised directly on the individual or its environment). Wilson (1980) proposed two other components - costs and benefits, and the extent to which each of them is concentrated or diffused was seen as a structuring element of politics. Yagade and Dozier (1990) distinguished among concrete and abstract issues, referring to the degree of difficulty to conceptualise a topic. An analysis of voting patterns by Carmines and Stimson (1980) brought forward another categorical division line - easy vs. hard issues. The first group comprises symbolic matters, which are often related to political goals, whereas the second refers to technical aspects, requiring expertise and associated with policy means. ${ }^{4}$

The applicability of such typologies has been tested on different polities and venues, but more often structuring dimensions or issue categories (especially Lowi's and Wilson's types) are taken for granted and used as independent variables in studies of political or policy activities. This underscores an assumption that a certain issue character line is emphasised by the relevant policy actors as a decisive structuring mode of policies. Whether the considered dimension is indeed applicable or whether another one is a better depiction of reality is an empirical question that sometimes remains untouched. This study aims at disentangling both the logic behind selection and highlighting of specific issue character and the consequences thereof for political attention in a case study of the EU.

\section{European Council agenda dynamics}

The European Council was first listed among the official EU institutions in the Treaty of Lisbon (signed in 2007) but has been conducting regular meetings ever since March 1975 and acting as the key top arena for political negotiation. It has been responsible for setting the direction of European integration via defining the general political guidelines for the Community, which more than once resulted in initiation of new common policies (Werts, 2008). Due to its impenetrable discussions, consensus decision-making method, and until recently, its informal status, studying agenda setting in the European Council has been difficult, and seemingly worthy only for scholars of law and institutional structure. Research on framing and information processing dynamics in the EU also tends to overlook the role of

\footnotetext{
${ }^{4}$ In the international relations literature, additional typologies have been developed to study state behaviour on foreign and defence policy matters. For example, Rosenau (1966) pioneered a distinction between tangible and intangible with respect to both the means to mobilise support and the kind of values that were allocated. Underdal (1979) identified three dimensions regarding the configuration of policy preferences on an issue: intensity of the values involved in deciding on a question, the level of disagreement over policy, and the subgroup concentration on the issue at hand. Such typologies, besides being actorcentred, are also less useful to wider spectrums of policy themes that go beyond the foreign policy domain.
} 
the European Council, although the importance of informal decision making is nowadays stressed (for an overview see Daviter, 2011, 2014).

Yet, this body has affected the development of the European integration process more than any other Community institution (Wessels, 2008a). While being legally unbinding documents, the Conclusions presented after every meeting have had direct impact on EU policy making (Eggermont, 2012). Over the years, the European Council has become the agenda setter of the EU, discussing every issue within and beyond the EU's competence framework (de Schoutheete and Wallace, 2002; Werts, 2008). The expectation that its role will continue to become bigger (van Grinsven and Melissen, 2002) has already begun to materialise. Examples thereof are the vital decisions the institution took in its attempts to counteract the recent financial crisis and mitigate its consequences.

Few recent studies reveal that the catalogue of themes discussed by this top EU body is extremely diverse, covering both issues within and outside EU jurisdictions (Wessels, 2008a, b; Nugent, 2010; Alexandrova et al., 2014). And yet, some issues appear to be overrepresented. The domains of foreign affairs, governance, and macroeconomics are not only the group occupying the highest proportion of attention but these domains are also said to condition attention to other issues (Alexandrova et al., 2012). The common feature of the three policy fields is that they all constitute core themes of government. Thus, the continuum of core vs. non-core matters to the functioning of a polity appears to be a driving line behind attention allocation. The finding is in line with research on executive agendas in five different European countries and the United States (Jennings et al., 2011). This suggests that particular types of agendas might be prone to similar character structures, giving additional leverage to the importance of empirically exploring issue character.

But is the suggested core-non-core themes dimension the only latent character explaining the allocation of attention in the European Council? If it were so, some critical moments in agenda-setting dynamics would be hard to explain. For example, why did the launching of the Social Agenda (more widely known as the Lisbon Agenda) gain so much attention at the European Council meetings in the year 2000? The employment and social policy matters contained in it cannot be classified as core themes, and did not appear to rise up to such a status during that time. The same can be said for the discussions of climate change (with a special reference to the EU position on international climate finance) in the second half of 2009 . Therefore, more systematic analysis of the nature of issue character behind the agenda of the European Council and the factors that influence character salience is needed. Moreover, the gradual institutionalisation of the body (Werts, 2008), changing political narratives (Foret, 2014), and the varying manner of expression in the Conclusions, in terms of focused discussions vs. vague language (Cloos, 2008), might suggest a rather volatile dimensionality of the agenda. Hence, the European Council is a challenging venue for applying the two-step agenda-setting model in the EU context but this makes the quest and its potential discoveries more compelling for the comprehensive validity of the model. 


\section{Data, approach, and methods}

The starting point of the backward-moving analysis is the agenda of the European Council, derived from the Conclusions circulated after the end of almost each meeting. ${ }^{5}$ This empirical material is utilised to disentangle issue character as a determinant of attention allocation in the European Council. The second step in the study explores changes in the salience of the discovered lines of issue character over time. Lastly, this information is used as a dependent variable in the final stage. Data on characteristics of the participants in the policy process and the context is employed to explain variation in saliency.

The data set of European Council Conclusions consists of 126 documents covering the period 1975-2012. The texts are coded at the quasi-sentence level following the EU codebook of the Comparative Agendas Project, which categorises issues in policy themes irrespective of tone and direction. The policy topics are classified in 19 general fields: agriculture, business, and internal trade, civil rights, defence, education, employment, energy, environment, foreign affairs, foreign trade, governance, ${ }^{6}$ health, immigration, law and crime, macroeconomics, regional policy, science and technology, social policy, and transport. ${ }^{7}$ The total number of quasi-sentences amounts to 43,587 , excluding statements without policy content.

In order to find out what lines of issue character structure the allocation of attention on the agenda of the European Council, we need a method that allows the extraction of dimensions from the data on political attention without preconceived ideas about the nature and number of these dimensions. The most appropriate method to apply is metric multidimensional scaling (MDS), since this technique aims to produce a spatial map of the 'hidden structure' of a data set on the basis of which the nature of the derived dimensions can be interpreted (Kruskal and Wish, 1978). One of the primary uses of this technique is in the field of psychology where respondents make judgements about similarity between different objects, for example countries, on the basis of which the underlying dimensions of judgement are revealed. The researcher then attempts to come up with a criterion explaining the decisions of the pool of participants, and thereby interprets the dimensions (Borg and Groenen, 2005). The approach here is analogous, in the sense that similarity in attention levels between policy topics is used as input for uncovering underlying dimensions. However, attention levels are not collected across space (i.e. participants) since the empirical interest of the study is focused on the European

\footnotetext{
5 Conclusions are not always published following an informal meeting.

6 The category 'governance' comprises matters like institutions and interinstitutional relationships, EU treaties and treaty reform, regulation of political life, bureaucratic oversight, government efficiency, political appointments, relationships between the EU and its member states, etc.

7 The original coding scheme includes two more categories. Since the total attention to each of them represents $<1 \%$ of the agenda, they were merged with other topics. Culture $(0.5 \%$ of the total attention) was combined with education, and public lands and water management $(0.1 \%)$ was merged with environment.
} 
Council as a collective body (rather than its members). Instead the data is organised across time, wherefore the Conclusions are combined into 74 equal periods of 6 months, corresponding to the Presidency chairmanships. ${ }^{8}$

As mentioned, the choice of the method is motived by the fact that MDS allows the inference of dimensions without having pre-defined attributes of these dimensions. ${ }^{9}$ The drawback of this approach is that the researcher is solely responsible for interpreting the visual depiction of the results. In the current study, this problem is at least partially circumvented by analysing determinants of the temporal variability in salience of one of the discovered dimensions. In this sense, the second step of the analysis serves as a further confirmation of the interpretation.

MDS uses proximities (i.e. differences or similarities) between objects to identify their position on the map. Since the attention of political actors is always scarce (Jones, 2001), emphasising one issue will inevitably result in deemphasising another one. This implies inseparability of the dimensions, wherefore the Euclidean MDS measure is chosen (Steyvers, 2002). Furthermore, its application appears suitable for data comprising relative emphasis on policy issues (see Veen, 2011). The computation of the similarity matrix used to extract the MDS solution is based on the proportions of attention to each of the 19 policy themes, per 6-month term, in the 74 identified Presidency periods. ${ }^{10}$ It should be noted that the results of classical MDS based on Euclidean distances are equivalent to the results of another commonly used technique for dimensionality reduction, Principal Component Analysis (Cox and Cox, 2001: 43-44). ${ }^{11}$

After performing MDS on the full data set and identifying the nature of the extracted lines of issue character, temporal MDS is carried out. This allows us to evaluate changes in saliency of the latent dimensions. Building on the work of Van der Brug (1999) and Baumgartner et al. (2008), temporal developments are evaluated with the help of subsequent overlapping time windows. Each time

${ }^{8}$ The total number of Presidencies in this 37-year timeframe is 76 but two of them did not produce any Conclusions. While the rotating Presidency system was changed for the European Council in December 2009, the same time slots are used for the remaining 3 years in order to make the periods comparable to the rest. Presidency biannual planning appears to be the most appropriate temporal division consisting of equal intervals.

9 The formula for Euclidean distances between shares of attention to policy themes is

$$
D\left(t, t^{\prime}\right)=\sqrt{\sum_{p=1}^{n}\left|t_{p}-t_{p}^{\prime}\right|^{2}}
$$

where $D$ is the distance between the agenda at time $t$ and the agenda at $t^{\prime}, t_{p}$ is the proportion of attention allocated to policy topic $p$ at time $t, t_{p}^{\prime}$ is the proportion attention allocated to policy topic $p$ at time $t^{\prime}$, and $n$ is the number of variables (74 biannual agendas).

${ }^{10}$ Count data instead of proportions could also be used. However, due to the changing length of the Conclusions over time, shares are considered a more appropriate point of departure.

${ }^{11}$ Factor analysis would not be an appropriate method here, since the matrix for the calculation of factors within it consists of correlation or covariance estimates between attributes, whereas the matrix used in the MDS approach is based on dissimilarity in attributes (i.e. the differences between attention fractions at $\left.t_{0}, t_{1}, t_{2} \ldots t_{n}\right)$. 
window consists of three consecutive semi-annual terms. An example of two periods, where substantial changes in dimensionality are detected, will be analysed qualitatively in order to explore the logic behind the change modes and confirm the utility of the dimension labelling.

The last stage attempts to explain the rises and falls in prominence of one of the unravelled latent dimensions. Data on the ideological composition of the European Council and indicators theoretically related to the nature of the discovered issue character line are used as predictors of the saliency fluctuations. A Tobit regression is computed due to the limited nature of the dependent variable and the short time frame for which data on the independent variables is available.

\section{Analysis of issue character}

A first step in the analysis is to determine the number of character lines 'hidden' in the data. The MDS solution produces 18 dimensions, ${ }^{12}$ with the first two having much higher eigenvalues. The squared eigenvalue accounts for $97.91 \%$ of the total dissimilarity. These results suggest that it might be sufficient to consider a twodimensional space, and an inspection of the scree plot of eigenvalues encourages this. Kruskal's Stress 1 test shows that the total stress of the two-dimensional solution is $0.15,{ }^{13}$ which is acceptable although somewhat low. A move to a threedimensional structure will only reduce the stress to 0.13 (i.e. within the same acceptability range) and lift up the cumulative per cent explained by the squared eigenvalue to 99.03. Therefore, the choice of a two-dimensional framework seems reasonable. In order to confirm that the dimensionality structure is not due to one or a few outliers, validation of the results displayed in the map is crucial. ${ }^{14}$ A splitsample check was performed on two samples of data including the agendas of every second and every third Presidency, respectively. Both new maps (not shown) are very similar to the original one, thus validating the results of the MDS structure on the full data.

The first dimension (D1) explains $90.17 \%$ of the dissimilarity in attention to topics on the European Council agenda (squared eigenvalues), and is thus the main type of issue character that determines the level of attention across issues. As Figure 2 shows, this dimension corresponds well to the findings of previous research (Alexandrova et al., 2012; see also Jennings et al., 2011). The key determinant of the allocation of attention in the European Council is the classification of topics as

\footnotetext{
12 The maximum number of dimensions equals $n-1$, where $n$ is the smaller of the number of rows and columns.

${ }^{13}$ A stress of 0 denotes perfect match between the data structure and the represented dimensions, whereas a stress of 1 would indicate no match at all.

${ }^{14}$ There are two main approaches to validation - regression of the 'attributes' on the dimensional coordinates or a split-sample check. The second approach involves conducting an MDS on one or more samples of the attributes and comparing the samples to the original model. It is considered a better validity check (Jaworska and Chupetlovska-Anastasova, 2009).
} 


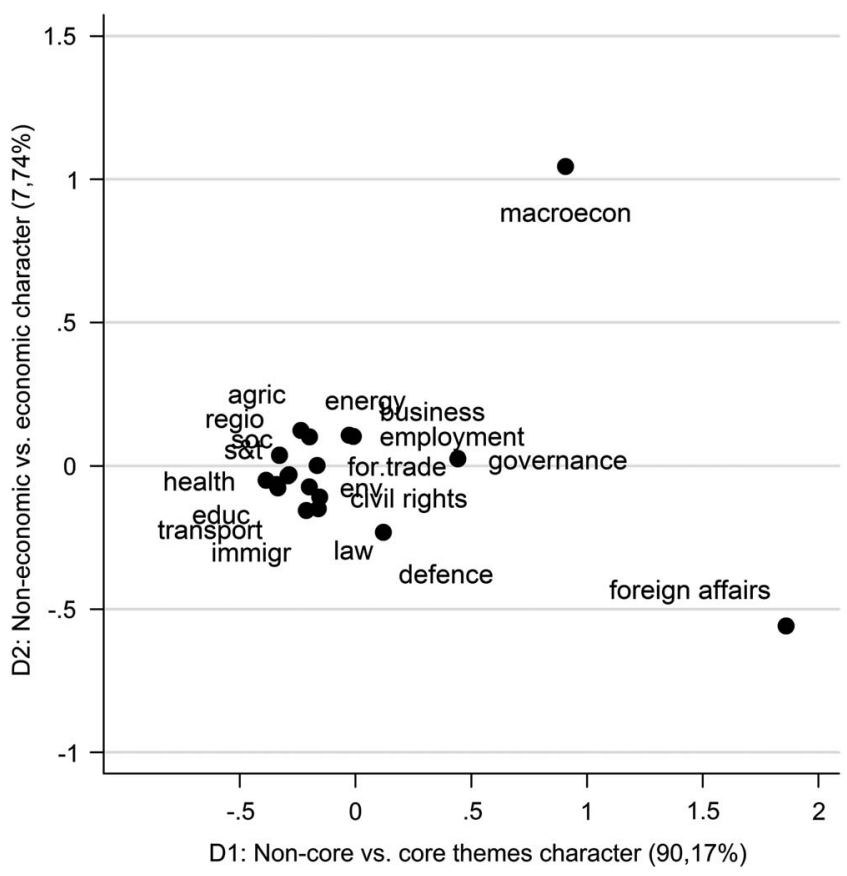

Figure 2 Classical metric MDS on European Council Conclusions, 1975-2012.

core vs. non-core functions of government. Core themes - foreign affairs, macroeconomics, and governance - occupy the positive extreme of the spatial map. Defence appears as an intermediary category on the continuum, suggesting that it can rise to a core function status but does not always do so. This seems logical considering the less crucial location of this domain as a government function within the EU competency framework compared with its member states. The non-core functions end of the dimension contains the rest of the issue categories. The distances between topics there are small, considerably smaller than those between the core themes, suggesting that changing the focus from one topic to another here is quite easy.

The second dimension (D2) explains $7.74 \%$ of the attention dissimilarity in the Conclusions (squared eigenvalues). Reading the dimension from top to bottom, the line starts with macroeconomics, and moves to a mix of expenditure and regulatory domains at some distance, then continues with interior policies - civil rights, law and crime, and immigration - and ends with defence and foreign affairs at the other extreme. This dimension seems to reflect the presence or lack of an economic character of the discussed issue. It follows Nugent's (2010: 281-282) crude classification of EU policies in two groups: economic and non-economic ones. This is a simplified version of the typology of EU policies proposed by Hix and Høyland (2011) consisting of five categories: expenditure (distributive and redistributive), 


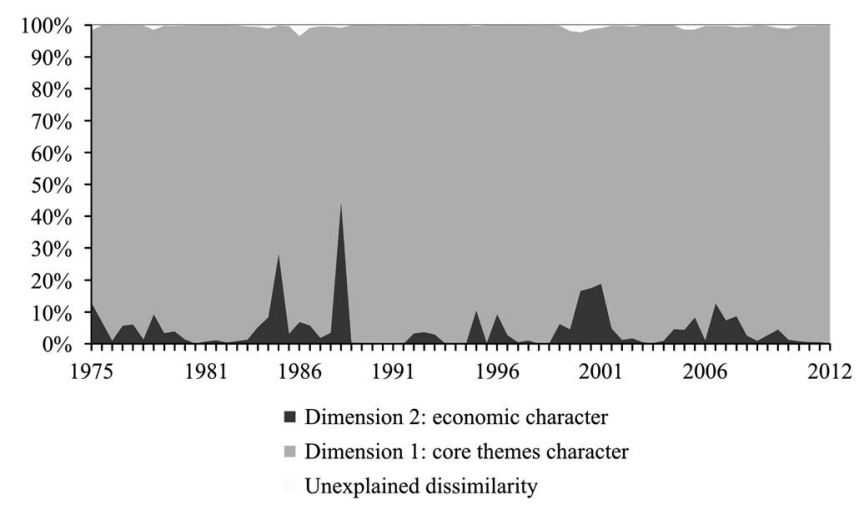

Figure 3 Temporal changes in prominence of issue character of the European Council agenda.

macroeconomic, regulatory, interior, and foreign policies. The close positioning on the MDS map of many topics of expenditure, regulatory, and interior policy types suggests that the crude generalisation of issues within a policy area might conceal blurring of policy types. For example, while in the EU agriculture would be foremost considered an expenditure policy, it also contains many regulatory aspects. Or the topic of foreign trade (the Community's Commercial Policy) includes the common customs tariff but also features political aspects such as measures towards a fair international trade system. An exploration of the longitudinal developments of this dimension can shed better light on the plausibility of the interpretation.

\section{Temporal changes in dimensionality}

The next step in the analysis is to conduct MDS on subsequent overlapping time windows of three terms in order to explore how the salience of issue character has evolved over time. Figure 3 displays the share of dissimilarity in attention explained by the first two dimensions. ${ }^{15}$ The temporal MDS analysis shows that the distinction between core and non-core themes has permanently been the most dominant type of issue character determining the allocation of attention. The second dimension underpinned by the economic character of the issues has also continuously played a role even if mostly a minor one. In a few periods though, it has demonstrated rises in importance, accounting for over 10 or $15 \%$ of the dissimilarity in attention. The highest peaks were in the first half of 1985 and second half of 1988, where economic character explained 28 and $45 \%$ of the attention dissimilarity, respectively. Thus, it seems that more often than not economic character has played a role in the motivation to distribute attention across issues in the European Council. While most of

15 The sum of the two does not equal $100 \%$ whenever additional dimensions account for the total explained variance. 
(a)

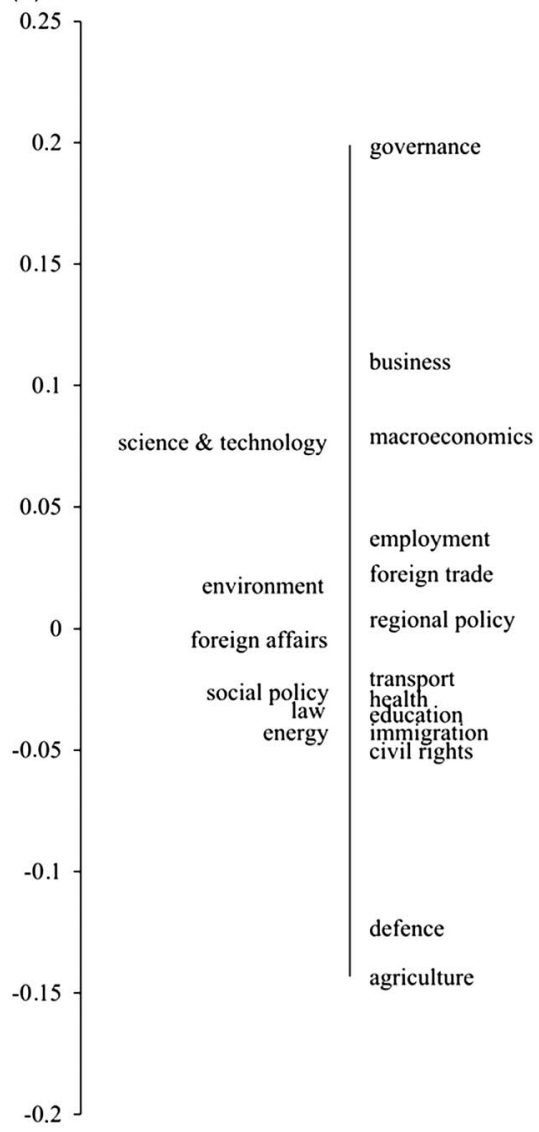

(b)

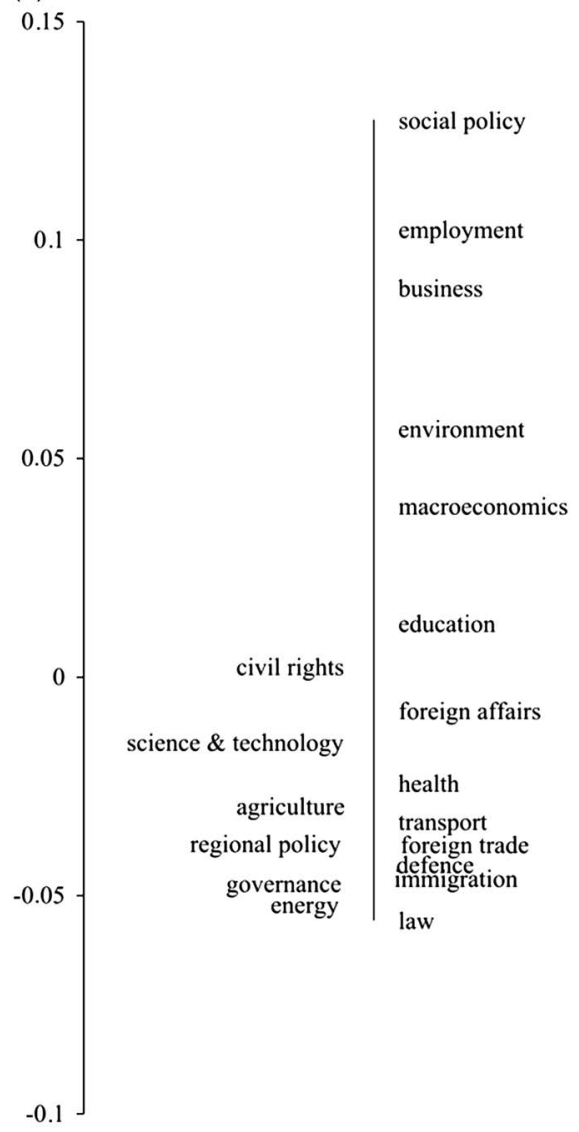

Figure 4 Economic issue character (D2) on temporal windows for presidencies 21(a) and 53(b).

the time its role has been negligible, in a few cases it has enjoyed stronger saliency, reducing the explanatory power of core themes as a character driving attention size. Before delving further into the reasons behind these shifts in the prominence of $D 2$, let us explore the placement of issues on it in two periods with a high fraction of explained dissimilarity - the first halves of 1985 and 2001.

During the period January-June 1985 (Presidency 21), the European Council held two meetings. The temporal dimensionality plot measuring the dissimilarity between this 6-month term and its subsequent and preceding ones, shows that the salience of D2 increased to $28.31 \%$. Figure 4 (a) presents the placement of issues on the economic character line. Several topics, in particular governance, business, and science and technology demonstrate a more pronounced economic character. A closer look at the specific issues discussed in the Conclusions confirms this logic. Two major aspects of governmental affairs were the reports by the ad hoc Committees on People's Europe and Institutional Affairs. Both of them had a strong 
focus on completing the Internal Market. This was the central topic within the category business as well. The theme science and technology featured a commitment to increase the Community resources for research and development and also showed a link to the Common Market. Thus, the prominence of the Single Market issue and the linking of other topics to it reflected an emphasis on the economic character of the agenda. Notably, the economic dimension was accentuated in reference to matters of both core and non-core themes.

Figure 4(b) presents D2 for the time window around the 53rd Presidency, covering the first half of 2001 . It explains $18.92 \%$ of the dissimilarity in attention, with rising elements of economic character in the areas of social policy, employment, business, and environment. Exploring the nature of the issues discussed at the two meetings, a special focus on modernising the European Social Model is visible. This framework included adaptation of social protection systems in the context of ageing populations, promotion of social inclusion, modernisation of labour markets, improvements in employment mobility, etc. The need to meet employment targets was also stressed. The acceleration of economic reform was envisaged, first of all, via exploiting the potential of the Internal Market. Besides that, the EU Sustainable Development Strategy set a focus on coordinating economic, social, and employment policies. In short, various topics became more prominent because they were presented in an economic light - drawing on economic targets and goals, leaning to the use of macroeconomic instruments, and linking performance in other sectors to economic policy.

Thus, the overall dimensionality structure of the European Council agenda constitutes a rather fixed space of two lines of issue character, the saliency of which, however, varies over time. While core issues always receive more attention, adding a stronger economic connotation to topics can also lead to higher attention. The key question is under what conditions the second dimension can rise in prominence. The next section proposes an answer to this question.

\section{Explaining salience of economic issue character}

In order to understand what drives the changing mode of salience in economic character, we need information about the European Council and its context, associated with economic matters. A first relevant factor could be the ideological composition of the body, measured in terms of overall left-right preferences. While previous research shows that most of the issues discussed by the European Council cut across the traditional party line, party politicisation in this institution is possible (Tallberg and Johansson, 2008). It seems logical to expect ideology to have an effect exactly on the economic character of the agenda, with a stronger emphasis of this dimension during more left-wing orientation periods. This expectation is based on the finding that a stronger economic issue character results in higher attention particularly to non-core themes, or a range of topics that are not within the macroeconomic domain. As the examples discussed in the previous section demonstrate, 
topics usually benefit from the rises in the salience of the economic dimension via a link to economic aspects. A social dimension was added to the Internal Market, research and development was addressed in the context of higher spending, and employment became a hot topic because of the perceived need to coordinate it with macroeconomic goals. Thus, the intrusion of economic attributes in areas, which are not strictly economic might be a seized opportunity by leftist governments to promote issues, which they usually care more about in the context of economic policies.

In order to measure the left-right position of the European Council at a given moment, a variable is constructed on the basis of the data in the Comparative Manifestos Project, classifying the position of political parties on this continuum on the basis of their electoral programmes (Volkens et al., 2011). Using information from the ParlGov database on the composition of national governments in every EU member state (Döring and Manow, 2012), the left-right standing of each individual government can be determined. The mean value of all member states is recorded as a general score for the right-left position of the European Council, available up to the first half of 2006. ${ }^{16}$ The overall expectation for ideology is the following:

HyPOTHESIS 1: The more left-wing the European Council, the more salient the economic character of its agenda.

Other factors with potential influence on the saliency of the economic character of the agenda can be derived from indicators for the state of the economy. In particular, it would be relevant to consider GDP growth, level of government deficit, unemployment, and consumer confidence in the economy. While the first measure is a standard way of estimating how well or bad the economy is doing overall, government deficit and unemployment have been relevant keywords in EU jargon over the course of the integration project and viewed with a sense of urgency. Adding consumer confidence includes a citizens' estimation of how well the economy is performing. Data on GDP growth of the EU is available via the Organisation for Economic Cooperation and Development and for the other three indicators, via Eurostat. Unfortunately, some estimates (government deficit and consumer confidence) are available only after 1995. Due to the annual availability of two indicators (government deficit and GDP growth), the yearly scores are assigned corresponding to each of the two biannual terms. The general expectation for all indicators is based on a problem - solution logic, with the European Council emphasising agenda items in economic terms whenever exacerbation of economic problems takes place and avoiding to do so in times of economic progress. In particular, this suggests the following hypotheses:

HYPOTHESIS 2: Rising GDP growth results in less salient economic character of the agenda.

\footnotetext{
${ }^{16}$ Due to missing data on some of the new member states and Greece since July 2004, the average calculation includes less than all countries.
} 
HYPOTHESIS 3: Rising government deficit leads to more salient economic character of the agenda.

HYPOTHESIS 4: Rising unemployment brings about more salient economic character of the agenda.

HYPOTHESIS 5: Rising consumer confidence results in less salient economic character of the agenda.

Last but not least, we need to control for changes in the institutional leeway in addressing issues, which can be measured via the total number of meetings per semester. The final data set covers 23 semesters in the period 1995 to mid-2006. Before estimating the regression equation, a number of data checks are performed, confirming normality and homoskedasticity of the residuals, ${ }^{17}$ stationarity of the data, lack of autocorrelation of the errors, ${ }^{18}$ and no multicollinearity across the independent variables. Therefore, an analysis via an OLS regression would have been justified. However, the dependent variable is bound between the theoretical values of 0 and 100 (minimum and maximum explained variance in MDS), which might yield inconsistent OLS regression estimates. A solution for this problem is to use Tobit, a censored regression where the upper and lower limits of the dependent variable can be pre-set. ${ }^{19}$ Table 1 presents the results. ${ }^{20}$

Two of the predictors - ideology and government deficit - have significant effects on the economic character of the agenda in the expected directions. For a one unit move towards the right side of the left-right ideological dimension of the European Council, the economic character of the agenda becomes less prominent with $1.51 \%$. A one unit increase in the government deficit (measured in net lending/borrowing as a percent of GDP) of the EU is associated with 2.29 units growth in the predicted value of economic character. GDP growth, unemployment, and consumer confidence do not have a statistically significant effect, and neither does the frequency of summit meetings.

Despite some inefficiencies in the data, especially the short time frame, the fact that a significant relationship with some predictors is found is remarkable. Overall, it seems that political ideology matters in the European Council when it comes to politicising issues in terms of economic character. One specific indicator also has an effect, but a range of others do not. Notably, government deficit, which has become a keyword in EU political rhetoric in the last few years, has already had an agendastructuring effect since at least the mid-1990s. The different patterns in the dependent variable until the early 1990s and ever since suggest that we should be careful

\footnotetext{
17 Breusch-Pagan/Cook-Weisberg test for heteroskedasticity is used.

18 No serial correlation is detected applying the Durbin-Watson statistic, as well as the Durbin's alternative and the Breusch-Godfrey tests.

${ }^{19}$ Fractional logit is another possibility but due to the low numbers of observations vis-à-vis dependent variables, Tobit is preferred.

${ }^{20}$ Applying the linktest command in Stata, the model appears to be correctly specified.
} 
Table 1. Explaining variation in the economic character of the European Council agenda, 1995-2006

\begin{tabular}{lr}
\hline \hline & \multicolumn{1}{c}{ Tobit } \\
\hline Right-left & $-1.505^{* * *}(0.363)$ \\
GDP growth & $1.048(2.150)$ \\
Government deficit & $2.286^{* *}(0.946)$ \\
Unemployment & $3.680(2.848)$ \\
Consumer confidence & $-0.173(0.540)$ \\
Nr. meetings & $-1.683(1.394)$ \\
Constant & $-19.311(25.951)$ \\
Observations & 23 \\
$R^{2}$ & 0.502 \\
Probability $>F$ & 0.000 \\
Log-likelihood & -64.746 \\
\hline \hline
\end{tabular}

Standard errors in parentheses.

$* * P<0.05, * * P<0.01$.

with generalisations over the full time period. The early years of the European Council when its agenda-setting role was less noticeable and the Community did not have such large competences might be subject to different explanations.

\section{Conclusion}

The central claim of this paper is that it is possible to unravel the factors determining the overall composition of political agendas if we rely on the notion of issue character as an intermediary step. The empirical value of this claim was presented on the basis of an analysis of political attention in the European Council, a crucial informal player in the EU with strong agenda-setting powers. The approach consists of two steps. It starts by examining the longitudinal spread of attention to policy topics across equal time periods, via a dimensionality reduction technique, with the aim of extracting the types of issue character that structure the level of attention. In the second phase, temporal changes in the salience of issue character are used as a dependent variable vis-à-vis a number of theoretically relevant predictors associated with the participants in the policy process and their context. Finally, the model consists of endogenous and exogenous factors that influence the saliency of issue character over time, which in turn determines the overall level of attention allocation to various topics on the agenda.

Analysing the content-coded Conclusions of the European Council, two issue character lines appear to structure the attention: core-non-core themes and economic-non-economic ones. The first dimension corresponds with findings of previous research and is in line with the primary role expectation for the institution - to draw the political framework for development of the EU. The second dimension is a real new finding, since although being mostly low-key sometimes it rises in saliency 
at the expense of its stronger counterpart. Thus, problematising certain issues in economic terms has led to more attention to these matters, even when they were non-core themes. The emphasis of economic elements in various issues is a reflection of the rising prominence of an economic issue character dimension of the agenda. The changing saliency in economic issue character can be explained by factors related to the participants in the agenda-setting process and their context. For the European Council, the political ideology of the body was used as a relevant example of the first, and a range of economic indicators as instances of the second. The results of the analysis covering the period 1995 to mid-2006 show a positive effect of left-wing positioning in the European Council and rising government deficit on the prominence of economic character and suggest that other economic indications, such as GDP growth, unemployment level, or consumer confidence do not play a role.

The empirical application of the two-step agenda-setting model demonstrates well the utility of using this approach in order to understand the logic behind overall agenda composition. But foremost, it reveals vital new information about the functioning of the European Council and its motives in discussing policy matters. We know now that the EU top body does not only dedicate substantial attention to the issues that are core to the functioning of the Community and its institutions and for their survival. Non-core themes can be defined as problems on another dimension - emphasising elements of economic character - and in this way gain prominence. The two brief case descriptions demonstrated how this happened for social policy, employment, environment, and other matters in two different periods. The necessary conditions for such issue character emphasis are found in a pro-leftist orientation of the European Council and increasing government spending, resulting in deficit.

The nature of the second dimension might not appear too surprising for EU scholars, as European integration has moved alongside economic terms with gradual spill-overs to other domains. Studies of issue portrayal have often found that an economic frame is prioritised in the EU context. Pursuing such an 'economization strategy' (Guigner, 2004) has appeared successful for issues originating in various policy domains, such as culture (Littoz-Monnet, 2012), health (Guigner, 2004), defence (Mörth, 2000), urban policy (Atkinson, 2001), biotechnology (Rhinard, 2010; Daviter, 2011), and gender equality (Black, 2009), to name a few. Because of this broad applicability of the economic frame, it is logical to infer that an economic issue character could have an influential role in EU policy making more generally. This might seem to suggest that the finding regarding the second dimension of the European Council agenda is not novel. However, framing case studies focus mostly on the European Commission. This core supranational body has always acted as a driver of integration, which spilled over from economic affairs to other domains. The European Council, the arena for national interests, is expectedly much more likely to prioritise issues of 'high politics' or the core themes of government. But the fact that an economic issue character also structures political attention in the European Council is remarkable and hints that this logic might apply across institutional settings in the EU. 
Our knowledge of how to bridge issue attention determinants with the broad composition of political agendas has moved a step ahead. Using the notion of issue character as a linking component appears a theoretically viable and empirically justifiable tool. Future research should expand the study of the functioning of the two-step agendasetting model towards other EU institutions, which can enable more fined-grained analyses of institutional interactions and informal distribution of tasks across EU levels. The approach should also be applied to extra-EU venues, as this can give insights into the cross-polity similarities in agendas and information processing.

\section{Acknowledgements}

The author would like to thank Anne Rasmussen, Marcello Carammia, Sebastian Princen and the three anonymous reviewers for their helpful comments. She is also grateful to Dimiter Toshkov for developing a CMP/ParlGov data extraction tool and assisting her with its use. An earlier version of this study is part of the author's dissertation 'Agenda Setting in the European Council'.

\section{References}

Alexandrova, P., M. Carammia and A. Timmermans (2012), 'Policy punctuations and issue diversity on the European Council agenda', Policy Studies Journal 40(1): 69-88.

Alexandrova, P., M. Carammia, S. Princen and A. Timmermans (2014), 'Measuring the European Council agenda: introducing a new approach and dataset', European Union Politics 15(1): 152-167.

Atkinson, R. (2001), 'The emerging 'urban agenda' and the European spatial development perspective: towards an EU urban policy?', European Planning Studies 9(3): 385-406.

Bachrach, P. and M.S. Baratz (1962), 'Two faces of power', The American Political Science Review 56(4): 947-952.

Baum, M.A. (2002), 'Sex, lies, and war: how soft news brings foreign policy to the inattentive public', American Political Science Review 96(1): 91-109.

Baumgartner, F.R., S.L. De Boef and A.E. Boydstun (2008), The Decline of the Death Penalty and the Discovery of Innocence, Cambridge: Cambridge University Press.

Birkland, T.A. (1997), After Disaster: Agenda Setting, Public Policy, and Focusing Events, Washington: Georgetown University Press.

Black, E.J. (2009), 'EU equality commitments and shifting meanings of gender equality', Review of European and Russian Affairs 5(1): 52-82.

Borg, I. and P.J.F. Groenen (2005), Modern Multidimensional Scaling: Theory and Applications, 2nd edn., New York: Springer.

Candel, J.J.L. G.E. Breeman, S.J. Stiller and C.J.A.M. Termeer (2014), 'Disentangling the consensus frame of food security: the case of the EU Common Agricultural Policy reform debate', Food Policy 44: 47-58.

Carmines, E.G. and J.A. Stimson (1980), 'The two faces of issue voting', The American Political Science Review 74(1): 78-91.

Cerna, L. and M. Chou (2014), 'The regional dimension in the global competition for talent: lessons from framing the European scientific visa and blue card', Journal of European Public Policy 21(1): 76-95.

Cloos, J. (2008), Analyse des conclusions du Counceil Europeen depuis 1979. Note interne.

Cobb, R.W. and C.D. Elder (1971), 'The politics of agenda-building: an alternative perspective for modern democratic theory', The Journal of Politics 33(4): 892-915.

Cox, T.F. and M.A.A. Cox (2001), Multidimensional Scaling, Boca Raton: CRC Press.

Daviter, F. (2011), Policy Framing in the European Union, Basingstoke: Palgrave Macmillan. 
(2014), 'An information processing perspective on decision making in the European Union', Public Administration 92(2): 324-339.

de Schoutheete, P. and H. Wallace (2002), Study on the European Council, Brussels: Notre Europe.

Döring, H. and P. Manow (2012), Parliament and Government Composition Database (ParlGov): An Infrastructure for Empirical Information on Parties, Elections and Governments in Modern Democracies. Version 12/10-15 October 2012. Retrieved 9 January 2014 from http://parlgov.org/

Eggermont, F. (2012), The Changing Role of the European Council in the Institutional Framework of the European Union: Consequences for the European Integration Process, Mortsel: Intersentia.

Foret, F. (2014), 'Legitimacy in numbers? Communicative aspects on the post-Lisbon EU', in F. Foret and Y. Rittelmeyer (eds), The European Council and European Governance. the Commanding Heights of the EU, London: Routledge, pp. 147-166.

Goffman, E. (1974), Frame Analysis. An Essay on the Organization of Experience, Boston: Northeast University Press.

Green-Pedersen, C. and P.B. Mortensen (2010), 'Who sets the agenda and who responds to it in the Danish parliament? A new model of issue competition and agenda-setting', European Journal of Political Research 49(2): 257-281.

Guigner, S. (2004), 'Institutionalizing public health in the European Commission: the thrills and spills of politicization', in A. Smith (ed.), Politics and the European Commission: Actors, Interdependence, Legitimacy, London: Routledge, pp. 96-115.

Hix, S. and B. Høyland (2011), The Political System of the European Union, 3rd edn., Basingstoke: Palgrave Macmillan.

Jaworska, N. and A. Chupetlovska-Anastasova (2009), 'A review of multidimensional scaling (MDS) and its utility in various psychological domains', Tutorials in Quantitative Methods for Psychology 5(1): 1-10.

Jennings, W. S. Bevan, A. Timmermans, G. Breeman, S. Brouard, L. Chaqués-Bonafont, C. Green-Pedersen, P. John, P.B. Mortensen and A.M. Palau (2011), 'Effects of the core functions of government on the diversity of executive agendas', Comparative Political Studies 44(8): 1001-1030.

Jeon, Y. and D.P. Haider-Markel (2001), 'Tracing issue definition and policy change: an analysis of disability issue images and policy response', Policy Studies Journal 29(2): 215-231.

Jones, B.D. (2001), Politics and the Architecture of Choice, Chicago: University of Chicago Press.

Jones, B.D. and F.R. Baumgartner (2005), The Politics of Attention. How Government Prioritizes Problems, Chicago: University of Chicago Press.

Kingdon, J.W. (1995), Agendas, Alternatives and Public Policies, 2nd edn., New York: HarperCollins College Publishers.

Kjellberg, F. (1977), 'Do policies (really) determine politics? And eventually how?', Policy Studies Journal 5(s1): 554-570.

Klüver, H. (2011), 'The contextual nature of lobbying: explaining lobbying success in the European Union', European Union Politics 12(4): 483-506.

Kruskal, J.B. and M. Wish (1978), Multidimensional Scaling, London: Sage.

Littoz-Monnet, A. (2012), 'Agenda-setting dynamics at the EU level: the case of the EU cultural policy', Journal of European Integration 34(5): 505-522.

Lowi, T.J. (1964), 'American business, public policy, case-studies, and political theory', World Politics 16(4): 677-715.

— (1972), 'Four systems of policy, politics, and choice', Public Administration Review 32(4): 298-310.

Mahoney, C. (2007), 'Lobbying success in the United States and the European Union', Journal of Public Policy 27(1): 35-56.

Mörth, U. (2000), 'Competing frames in the European Commission - the case of the defence industry and equipment issue', Journal of European Public Policy 7(2): 173-189.

Moschella, M. (2011), 'Getting hedge funds regulation into the EU agenda: the constraints of agenda dynamics', Journal of European Integration 33(3): 251-266.

Nugent, N. (2010), The Government and Politics of the European Union, 7th edn., Basingstoke: Palgrave Macmillan.

Peters, B.G. (1994), 'Agenda-setting in the European Community', Journal of European Public Policy 1(1): 9-26. 
- (2001), 'Agenda-setting in the European Union', in J. Richardson (ed.), European Union. Power and Policy-Making, 2nd edn., London: Routledge, pp. 77-94.

Plein, L.C. (1991), 'Popularizing biotechnology: the influence of issue definition', Science, Technology \& Human Values 16(4): 474-490.

Princen, S. (2007), 'Agenda-setting in the European Union: a theoretical exploration and agenda for research', Journal of European Public Policy 14(1): 21-38.

- (2010), 'Venue shifts and policy change in EU fisheries policy', Marine Policy 34(1): 36-41.

Rhinard, M. (2010), Framing Europe: The Policy Shaping Strategies of the European Commission, Dordrecht: Martinus Nijnhoff Publishers.

Rochefort, D.A. and R.W. Cobb (1994), The Politics of Problem Definition: Shaping the Policy Agenda, Lawrence, KS: University of Kansas Press.

Rosenau, J.N. (1966), 'Pre-theories and theories of foreign policy', in R.B. Farrell (ed.), Approaches to Comparative and International Politics, Evanston: Northwestern University Press, pp. 27-92.

Schattschneider, E.E. (1960), The Semi-Sovereign People: A Realist's View of Democracy in America, New York: Holt, Rinehart and Winston.

Scholten, P. and A. Timmermans (2010), 'Setting the immigrant policy agenda: expertise and politics in the Netherlands, France and the United Kingdom', Journal of Comparative Policy Analysis: Research and Practice 12(5): 527-544.

Sheingate, A.D. (2000), 'Agricultural retrenchment revisited: issue definition and venue change in the United States and European Union', Governance 13(3): 335-363.

Sigelman, L. C.K. Sigelman, B.J. Walkosz (1992), 'The public and the paradox of leadership: an experimental analysis', American Journal of Political Science 36(2): 366-385.

Steyvers, M. (2002), 'Multidimensional scaling', in Lynn Nadel (ed.), Encyclopedia of Cognitive Science, London: Nature Publishing Group.

Strom, E. and A. Cook (2004), 'Old pictures in new frames: issue definition and federal arts policy', Review of Policy Research 21(4): 505-522.

Talbert, J.C. and M. Potoski (2002), 'Setting the legislative agenda: the dimensional structure of bill cosponsoring and floor voting', The Journal of Politics 64(3): 864-891.

Tallberg, J. and K.M. Johansson (2008), 'Party politics in the European Council', Journal of European Public Policy 15(8): 1222-1242.

Underdal, A. (1979), 'Issues determine politics determine policies: the case for a 'rationalistic' approach to the study of foreign policy decision-making', Cooperation and Conflict 14(1): 1-9.

Van der Brug, W. (1999), 'Voters' perceptions and party dynamics', Party Politics 5(2): 147-169.

van Grinsven, P. and J. Melissen (2002), 'Europese raad tussen marginale aanpassing en radicale hervorming', Internationale Spectator 56(9): 421-425.

Veen, T. (2011), 'The dimensionality and nature of conflict in European Union politics: on the characteristics of intergovernmental decision-making', European Union Politics 12(1): 65-86.

Volkens, A. O. Lacewell, P. Lehmann, S. Regel, H. Schultze and A. Werner (2011), The Manifesto Data Collection. Manifesto Project (MRG/CMP/MARPOR), Berlin: Wissenschaftszentrum Berlin für Sozialforschung (WZB).

Wendon, B. (1998), 'The Commission as image-venue entrepreneur in EU social policy', Journal of European Public Policy 5(2): 339-353.

Werts, J. (2008), The European Council, London: John Harper Publishing.

Wessels, W. (2008a), Das Politische System Der Europäische Union, Wiesbaden: VS Verlag.

- (2008b), The European Council: a bigger club, a similar role?', in E. Best, T. Christiansen and P. Settembri (eds), The Institutions of the Enlarged European Union: Continuity and Change, Cheltenham: Edward Elgar, pp. 16-33.

Wilson, J.Q. (1973), 'Organizations and public policy', in J.Q. Wilson (ed.), Political Organizations, New York: Basic Books, pp. 327-347.

— (1980), 'The politics of regulation', in J.Q. Wilson (ed.), The Politics of Regulation, New York: Basic Books, pp. 357-394.

Yagade, A. and D.M. Dozier (1990), 'The media agenda-setting effect of concrete versus abstract issues', Journalism Quarterly 67(1): 3-10. 